\title{
A CONSCIENTIZAÇÃO DO HOMEM PARA UMA EXPLORAÇÃO SUSTENTÁVEL DO MEIO AMBIENTE
}

\author{
Man awareness for a sustainable environmental exploitation
}

Dominique Rodrigues Barros - UNIFIMES/Brasil Monique Nogueira da Silva - UNIFIMES/Brasil

RESUMO: Este artigo tem o objetivo de compreender historicamente as relações do homem com o meio ambiente, propondo a conscientização do homem à exploração sustentável. É um trabalho de cunho bibliográfico, que visa mostrar as relações entre o homem e o meio ambiente através das diferentes formas que se desenvolveram a partir do seu período histórico e cultural. Diante disso, é dada uma preocupação acerca dos danos ambientais provocados pelo homem na contemporaneidade. Nesse mesmo sentido, é necessário que o homem produza estratégias de conscientização, planejamento e desenvolvimento sustentável, para que assim possa tentar diminuir os danos provocados ao meio ambiente e também desenvolver técnicas para que o mundo continue a evoluir sustentavelmente, analisando formas de redução dos efeitos negativos em relação ao meio ambiente, que acaba por refletir na vida do homem.

Palavras-chave: Ambiente. Desenvolvimento sustentável. Estratégias. Homem.

ABSTRACT: This article aims to understand historically the relationship of man to the environment, proposing the awareness of man to sustainable exploitation. It is a bibliographical work that aims to show the relationships between man and the environment through the different forms that have developed from their historical and cultural period. Given this, a concern is given about the environmental damages caused by man in the contemporary world. In the same sense, it is necessary for man to produce strategies of awareness, planning and sustainable development, so that he can try to reduce the damages caused to the environment and also to develop techniques for the world to continue to evolve sustainably, analyzing ways of reducing the effects negative in relation to the environment, which ultimately reflects in the life of man.

Keywords: Environment. Sustainable development. Strategies. Men.

\section{INTRODUÇÃO}

O objetivo da ecologia humana é buscar compreender as relações entre o homem e o meio ambiente, sendo uma tecnologia para que possamos agir de maneira sustentável no planeta, meio que irá garantir nossa sobrevivência, através da conscientização e mecanismos de utilização sustentável dos recursos naturais (ALVIN; BADIRU; MARQUES, 2014). 
Os danos ecológicos causados pelo uso descontrolado do ser humano de matérias naturais causam grandes efeitos negativos no ecossistema e na vida do homem na terra. Sendo assim este trabalho tem como objetivo compreender como se dá a relação do homem e o meio ambiente e o que pode ser feito através da conscientização para que possamos viver em prol de um desenvolvimento sustentável.

Segundo Ross e Becker (2012), a forma como o ser humano está lidando com o meio ambiente está provocando no nosso ecossistema grande transformações, tanto de ordem climática como nas áreas produtivas de alimento. $\mathrm{O}$ ser humano está utilizando intensificada mente os recursos naturais, devido a maneira como a humanidade escolheu para viver.

A sociedade contemporânea está passando por um momento onde muitas vezes utilizamos comportamentos de consumismo exagerado, onde o ser humano vive em atividade de usar os recursos naturais até a sua exaustão, fato que leva a elevados números de produção de lixo e poluição no meio ambiente.

Desta forma, o ser humano se encontra em situação muitas vezes de nãoconscientização de sua responsabilidade perante ao que pode causar no funcionamento do nosso ecossistema, o que merece a compreensão histórica da ecologia humana, e os aspectos envolvidos na relação entre homem e meio ambiente para que assim possamos contribuir na criação de estratégias de intervenção para uma exploração sustentável.

A escolha deste tema tem bastante importância para nossa sociedade contemporânea, pois observamos que o homem se torna cada vez mais destrutível em relação ao meio ambiente, o que provoca danos no desenvolvimento da civilização humana, para tanto foi utilizado como forma de pesquisa a revisão de literatura como descrito a seguir. O presente artigo adota como metodologia o estudo de revisão de literatura sobre a contribuição da ecologia humana, buscando refletr como se dá a relação entre homem e meio ambiente, numa perspectiva histórica e cultural.

Com isso os estudos em relação ao homem e meio ambiente contribuem para que possamos entender como o homem pode colaborar nos aspectos sociais, visando o desenvolvimento de estratégias sustentáveis, onde o homem possa viver e desenvolver, porém de formas que não alterem de maneira negativa o funcionamento natural do ecossistema. Para tanto foi utilizado pesquisas bibliográficas em livros, artigos, teses, monografias e arquivos via internet. 
A conscientização do homem para uma exploração sustentável do meio ambiente

\section{ASPECTOS HISTÓRICOS E CONCEITUAIS DA ECOLOGIA HUMANA}

A palavra ecologia humana foi assumindo significados e conceitos durante sua evolução, porém a partir do século XX o significado da palavra ecologia começou a dar passos importantes para os estudos realizados hoje sobre a relação entre o ser humano e o ambiente, sendo que antes seu significado se restringia apenas à biologia, e muito pouco para questões humanas, porém a ecologia foi assumindo e incorporando espaço nas demais ciências (DALLABONA; DALLABONA, 2007).

De acordo com Capra (1996), o ecologista Tanksey introduziu o termo "ecossistema", onde subsequentemente também inseriu na sua abordagem sistêmica a biologia, física moderna e a psicologia.

Nos anos 70 surge o termo "Ecologia profunda", citado por Arne Naess. A ecologia profunda era uma rede filosófica que lidava como seres humanos e qualquer outra coisa como sendo parte da natureza, não os separando. Ela acredita no mundo como uma rede de fenômenos que estão fundamentalmente interconectados (CAPRA, 1996).

A ecologia humana surge como parte da ecologia, porém não é necessariamente considerada como uma ramificação inserida dentro da ecologia. Acontece algumas divergências entre autores sobre o objetivo da ecologia humana, alguns defendem que o objetivo principal da ecologia humana é entender o comportamento humano sob variáveis ambientais, já outros consideram que a mesma transcende a ecologia e a própria biologia (BEGOSSI, 1993).

A ecologia humana surge com o intuito de compreender o sujeito e o meio ambiente, e como se dá a relação entre ambos, através de uma base filosófica sobre o entendimento entre espaço e tempo no desenvolvimento do sujeito e do coletivo. Nesse mesmo sentido, é evidente a sua relevância na evolução da informação das ciências consideradas não tecnológicas, causando uma revolução acadêmica tanto para a sociologia quanto para a antropologia, que por sua vez a ecologia contribuiu com o novo marco científico com base integracionista (ALVIM; BADIRU; MARQUES, 2014).

Para fins de definição do termo ecologia, Cassini (2005) e Dellabona e Dallabona (2007) afirmam que a palavra surge de duas palavras gregas: oikós que significa casa, e logos que significa estudo, sendo assim a ecologia é a ciência do habitat, que estuda as condições de existência dos seres vivos e as interações, de qualquer natureza, existentes 
entre esses seres vivos e seu meio, sendo que a ecologia humana pode ser compreendida como a ciência que busca compreender as conexões entre o homem e o meio ambiente.

De acordo com Cassini (2005) a primeira vez que foi usado o termo ecologia foi pelo biólogo alemão Haeckel. Nesse mesmo sentido Alvim (2008) afirma que no ano de 1870, o biólogo Ernest Haeckel sugeriu o termo ecologia como sendo ciência, onde o estudo era focado no reino vegetal e animal, porém o mesmo incorporou o caráter humanista na década do século XX.

De acordo com Alvim, Badiru e Marques (2014, p.86) a ecologia humana é um estudo apropriado para nossos dias atuais, onde deve ser usado com sabedoria para que promova a sobrevivência e preservação do nosso planeta. Em relação a isso pode se considerar que a Ecologia Humana é o estudo das relações dos seres humanos com o ecossistema e suas consequências.

Sendo assim, a ecologia humana é uma ciência que busca a compreensão da conexão entre o ser humano e meio ambiente, com objetivo de entender como se dá as relações em busca da promoção da sustentabilidade e sobrevivência do nosso planeta terra.

A nossa sociedade sofreu por uma grande alteração em relação ao modo de produção, o que foi marcado pelo período da Revolução Industrial, como afirma Campos (2006, p.2) "Foi a Revolução Industrial, que marcou a transição entre a sociedade agrícola-artesanal do Séc. XVIII para a sociedade urbano-industrial, que alterou profundamente as relações de produção, exatamente entre 1750 e 1830 ”.

Com isso ocorreu o surgimento do mercado mundial, e com ele acarretou várias consequências, como a comercialização de coisas que antes eram por direito de acesso a todos os seres humanos que ali pertenciam, como afirma Campos (2006, p.2):

\begin{abstract}
Agora a água gera energia e ambas são comercializadas. A terra ampla que poderia matar a fome de tantos, está improdutiva no latifúndio. As praias estão cercadas por condomínios de luxo ou por hotéis 5 estrelas. As florestas e o cerrado dão lugar à monocultura da soja ou à pecuária...a concentração da renda, a acumulação do capital vão gerando a injustiça que resulta na fome, na miséria, na violência, no desemprego, na infelicidade (CAMPOS, 2006, p.20).
\end{abstract}

As escrituras bíblicas sofreram alterações acerca de como os mandamentos escritos lidavam com a relação que o homem deveria ter com o meio ambiente em que 
vive, distorcendo o que era para ser algo harmonioso em egocentrismo, como acrescenta Campos (2006, p.3) “O que era dádiva, o homem transformou em propriedade. Excluiu o que não servia aos seus propósitos imediatos, tanto outros homens, como os bens naturais. Feriu, matou, destruiu, transformou amor em ódio".

Nesse sentido, nota-se que o homem está passando por um momento de grandes mudanças ambientais, que muitas delas causam impactos ambientais que interferem no bem-estar dos seres humanos e que futuramente ameaça a sobrevivência de todas as espécies na terra. $\mathrm{O}$ homem está por destruir o seu próprio lar que é a terra.

Estudar o passado, compreender o equívoco humano de centrar-se apenas na acumulação de bens, gerando exclusão e miséria, é fundamental se queremos educar e conscientizar as pessoas na direção de um novo comportamento ambiental, de um novo modo de vida, mais solidário, mais assentado no "ser", no respeito às diferenças, na aceitação e na tolerância. A terra não é uma propriedade particular de alguns (BOFF, 1998).

A partir da década de 1970 surgiram as primeiras preocupações relacionadas ao meio ambiente como um fenômeno social, concedido pela combinação de fatores como: a crise do petróleo e o consequente alerta ao esgotamento dos recursos naturais; as deliberações e a repercussão da $1^{\circ}$ Conferência Mundial das Nações Unidas sobre o Homem e o Meio Ambiente; os primeiros relatórios científicos questionando os limites do crescimento econômico em relação à capacidade de suporte dos ecossistemas e a aparição do movimento ambientalista (LEFF, 2001; NEDER, 2002).

A crítica do estabelecimento da questão ambiental guiava para um conflito entre o crescimento econômico e a preservação dos recursos naturais que resultaria em limites à continuidade do crescimento econômico. Nesse mesmo sentido, foram elaborados conceitos que refletissem a busca por harmonizar a atividade humana em suas relações com a natureza, como é o caso do Desenvolvimento Sustentável que vamos discutir no presente artigo (MOLINA; LUI; SILVA, 2007).

\section{O HOMEM E O MEIO AMBIENTE NA CONTEMPORANEIDADE}

Nos dias atuais nos deparamos com vários problemas ambientais, onde o ser humano ser tona responsável por grande maioria deles, devido seu grande consumismo e falta de conscientização acerca de suas atitudes que podem prejudicar de forma drástica o nosso ecossistema. Nesse mesmo sentido Ross e Becker (2012) afirmam que atualmente 
o mundo passa por alterações negativas tanto de ordem climática quanto nas áreas de produção alimentícia, que são consequências da maneira que o ser humano escolheu por viver, no qual utiliza de maneira exacerbada os recursos naturais do planeta.

Vivemos em uma sociedade consumista, urbana e industrial, onde muitos indivíduos se colocam em posição de aquisição de bens, muitas vezes sem nem precisar tê-lo, como afirma Kupstas (1997, p.99) "Contudo, como não conhecemos tal produto nem estamos habituados a usá-lo, e muitas vezes nem sequer precisamos dele, é preciso que se faça criar em cada um de nós a necessidade de consumi-lo, e é preciso que tenhamos meios para consumi-lo".

Vivemos em uma sociedade consumista, onde cria-se a necessidade de sempre ter que adquirir bens materiais, e com isso ocorre o crescimento econômico dos grandes potenciais comerciais e como consequência o devassamento exacerbado das matérias naturais. Desta maneira Albuquerque (2007) afirma que a característica da sociedade de consumo atual é a forma de lidar com os bens materiais, sendo que a quantidade de bens e serviços é além da necessária. Sendo assim, o consumismo é caracterizado pela utilização dos recursos naturais até a sua exaustão, de maneira que não supra apenas as necessidades básicas dos seres humanos, mas também as fúteis e de nenhuma relevância para sua sobrevivência. Desta forma, nota-se a necessidade de minimizar os efeitos causados pela produção desenfreada de bens, no qual aumenta a produção de lixo e poluição no planeta. Tal aumento desenfreado destes efeitos aconteceu após a expansão imperialistas.

Nesse sentido, observa-se que a sociedade se torna extremamente consumista, o que atinge de forma direta os recursos naturais até causar a exaustão da mesma, sendo necessário propor estratégias para que possamos fomentar novos caminhos para uma exploração sustentável dos recursos naturais.

É necessário que haja um controle da exploração dos recursos naturais, pois os mesmos são de ordem finita e não infinita. Os resultados da exaustão desses recursos são expressos também devido ao aumento exacerbado da população mundial, onde dados publicados pela Departamento de Assuntos Econômicos e Sociais da ONU no relatório de 2017 indica que a população no ano de 2017 se encontra com 7,6 bilhões deverá atingir 8,6 bilhões em 2030, 9,8 bilhões em 2050 e 11,2 bilhões em 2100. Apesar dos níveis de fertilidade continuarem declinando, o aumento de população tende a aumentar, sendo que 
aproximadamente 83 milhões de indivíduos são adicionados a população mundial (UN DESA, 2018).

Figura 1- População mundial

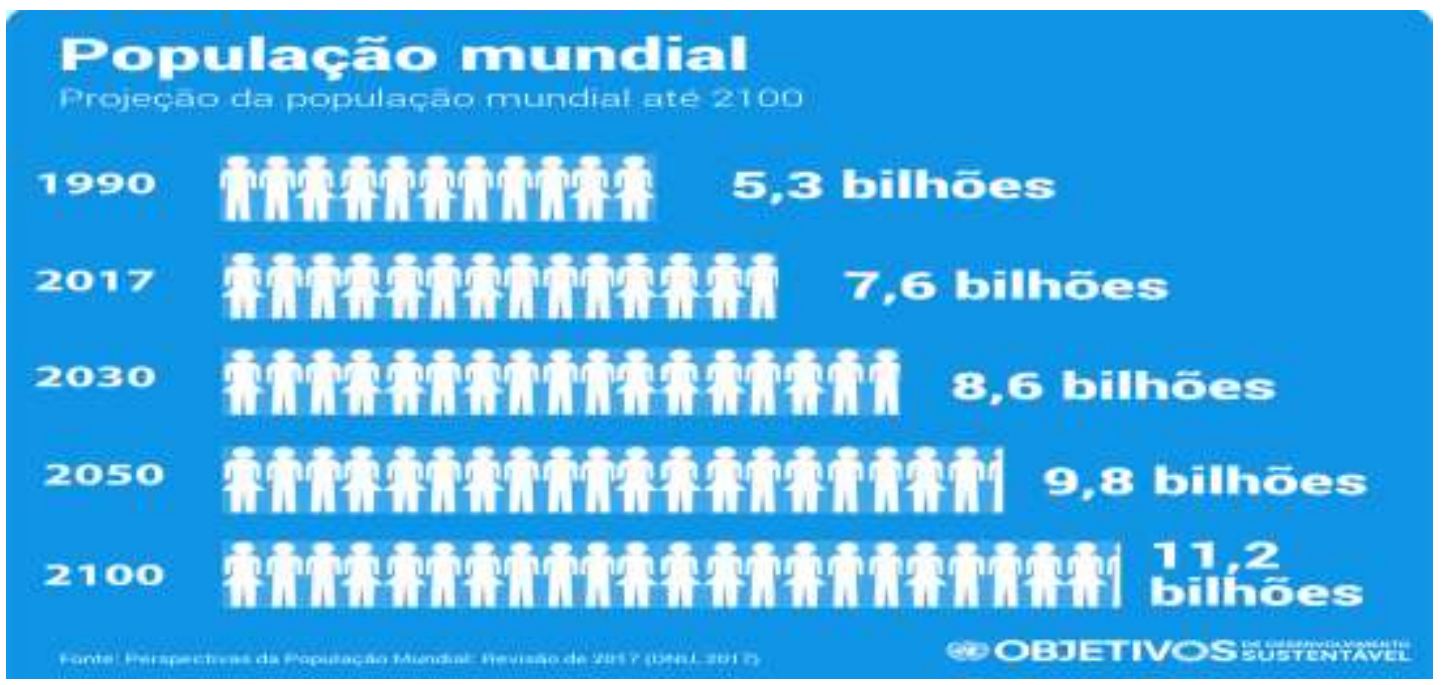

Fonte: ONUBR NAÇÕES UNIDAS DO BRASIL. Apesar de baixa fertilidade, mundo terá 9,8 bilhões de pessoas em 2050. 2018.

Com o aumento da população, a demanda por alimentos, água e abrigo também crescem, resultando em mais exploração dos recursos naturais, para que possa suprir as necessidades humanas. Nos últimos anos devido ao aumento da economia mundial e consumo, as despesas mundiais cresceram desde os anos 1970 cerca de 3\% ao ano. Os números dobraram desde o ano de 1973 e 1998, o que resultou em um aumento do consumo populacional como comida, abrigo, água e outros setores do desenvolvimento humano. Porém, grande parte deste consumismo se reverte mais a "vontades" do que a "necessidades", ou seja, o ser humano está utilizando mais do que precisa para sua sobrevivência, o que resulta em uma exploração dos recursos naturais além do que a mesma poderia oferecer (MMA, 2016).

De acordo com os dados publicados pela Global Footprint no ano de 2010 o consumo da população equivale a 1,5 planetas e a expectativa é que no ano de 2050 este número cresça para 3 planetas (GLOBAL FOOTPRINT, 2014, p.1), como mostra na imagem a seguir.

Figura 2 - Crescimento do consumo 1. 


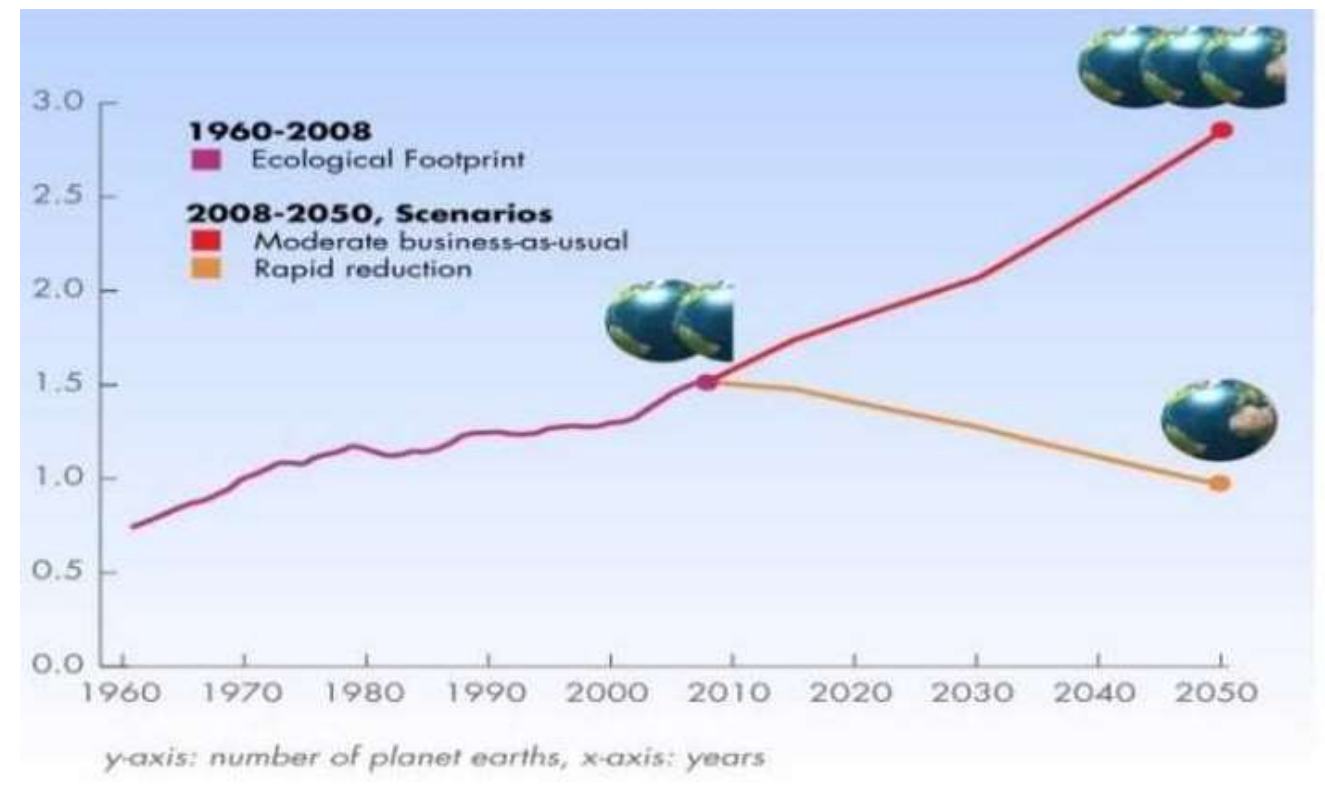

Fonte: Global Footprint Network, 2014, p. 1.

Através desta perspectiva futurística, é necessário criar meios para que haja uma exploração sustentável e rentável, pois caso contrário não será possível oferecer qualidade de vida para todos os seres que habitarem a terra. A educação ambiental da comunidade e das novas gerações é um dos meios de suma importância para que haja uma conscientização de novos modos de vida, que sejam mais voltados a manutenção do nosso ecossistema, que por meio de um Planejamento Ambiental cria-se meios para manter o planeta em equilíbrio.

\section{EDUCAÇÃO, CONSCIENTIZAÇÃO E PLANEJAMENTO AMBIENTAL}

O planejamento ambiental tem como objetivo realizar: gestão estratégica, planejamento socioambiental, inclusão social, educação ambiental, responsabilidade compartilhada e outros (ALVIM; BADIRU; MARQUES, 2014).

Pode ser definido como um conjunto de recursos com o objetivo de criar funções disponíveis que ajudem a manter um meio ambiente equilibrado e compatível com as atividades econômicas. Sendo assim, o planejamento ambiental deve ser contínuo, contendo três segmentos: antítese, análise e síntese do saber ambiental, que tem como objetivo fazer decisões que sejam focadas no desenvolvimento sustentável ambiental (ALVIM, BADIRU E MARQUES, 2014). 
Nesse mesmo sentido Souza \& Silva (2010) compreende o planejamento ambiental como sendo a busca pela preservação e conservação dos nossos recursos naturais. O planejamento ambiental é todo o planejamento que surge do princípio da valoração e conservação de bases naturais de certo território como bases de autosustentação da vida e das interações que a mantém.

De acordo com Albuquerque (2007) a educação ambiental usualmente é compreendida como um âmbito da educação que tem como proposito semear a compreensão sobre o ecossistema, buscando formas de auxiliar a sua preservação e meios sustentáveis na utilização de seus recursos. Da mesma forma que André Trigueiro (2005, p.263) acrescenta:

Somos escravos de um olhar reducionista, que relega muitas vezes, à natureza a função de apenas nos suprir de alimentos, energia, matéria-prima e belas paisagens. Dilapidamos o patrimônio natural sem a percepção de que somos parte do planeta, de que o meio ambiente começa no meio da gente, a partir da nossa constituição física, e de que a água, o ar, o solo e a luz solar são elementos fundamentais à manutenção da vida. (...) É preciso comunicar esse saber, traduzi-lo sem o peso do jargão ecológico-científico, torná-lo inteligível ao maior número possível de pessoas, a fim de que uma nova cultura se manifeste na direção da sustentabilidade. De que vale o saber se não sabemos comunicá-lo?

É preciso que tenhamos consciência e sensibilidade ao ponto de entender que o que nos mantem vivos são os elementos água, terra, ar e fogo em sua forma íntegra. Nesse mesmo sentido Ross e Becker (2012) define a Educação ambiental como sendo uma metodologia onde o sujeito assume papel ativo no processo de ensino/aprendizagem, no qual todos devem buscar o diagnóstico, análise e solução para os problemas ambientais. Além do mais, a Educação Ambiental deve oferecer a toda comunidade a informação e possibilidade para que todo cidadão seja transformador e ativo, através do desenvolvimento de habilidades e competências e por meio dos nossos comportamentos éticos e condizentes ao exercício da cidadania.

A causa mais relevante dos problemas sócio- ambientais é devido a produção de produtos desnecessários e danosos para a qualidade de vida e o consumo exagerado de uma pequena parte da população do mundo. Sendo assim, o recurso para salvar o planeta vai além da preservação das espécies de animais e vegetais, e sim a de fomentar a reflexão sobre ações que possam transformar as relações políticas, socioeconômicas e culturais entre os seres humanos e a natureza (REIGOTA, 2004). 
A educação ambiental tem como objetivo orientar e motivar os indivíduos a procurarem soluções para os problemas que surgem com relação ao meio ambiente, como afirma Albuquerque (2007, p. 88) “A educação ambiental deve orientar-se para a comunidade e procurar incentivar o indivíduo a participar ativamente da resolução dos problemas em seus contextos específicos. "

A educação ambiental por si só não irá resolver os problemas já causados pelo homem ao meio ambiente, mas poderá ajudar na conscientização para que desenvolvamos estratégias para os danos já causados e também para o desenvolvimento sustentável. Com a conscientização dos problemas ambientais globais e com a atuação na sua comunidade, haverá mudanças no sistema (REIGOTA, 2004).

Dessa maneira é possível que através da educação ambiental possamos criar uma consciência humana acerca dos processos envolvidos entre o que é realmente necessário para o homem, e o que é desnecessário e produz o que chamamos de problemas ambientais.

Para que aconteça uma mudança de comportamento dos seres humanos, deverá ser traçada uma estratégia para o desenvolvimento sustentável humano e da natureza, sendo assim é necessário a implementação de programas capazes de apresentar a importância da educação ambiental e adoção de práticas que busquem a sustentabilidade e a diminuição de impactos que as atividades humanas venham a ter no ecossistema. Através do debate amplo e profundo das necessidades humanas e um correto entendimento de que a forma como atuamos hoje, só nos levará para a destruição e o aniquilamento, será possível uma mudança de paradigma e com isso a introdução de um desenvolvimento sustentável em todas as esferas: política, econômica, social e principalmente ambiental (ROSS; BECKER, 2012).

\section{DESENVOLVIMENTO SUSTENTÁVEL}

Existem várias maneiras de definir o desenvolvimento sustentável, porém a Comissão Mundial para o Meio Ambiente e Desenvolvimento, criada pela ONU, apresenta o desenvolvimento sustentável como sendo ações que auxiliam nas necessidades atuais sem prejudicar as possibilidades de gerações futuras atenderem a suas próprias necessidades (DALLABONA, 2006).

Educação, Psicologia e Interfaces, Volume 3, Número 2, p. 121-135, Maio/Agosto, 2019.

ISSN: 2594-5343. DOI: https://doi.org/10.37444/issn-2594-5343.v3i2.131 
A conscientização do homem para uma exploração sustentável do meio ambiente

Nesse sentido, o desenvolvimento sustentável pode ser definido como o desenvolvimento de ações voltadas as necessidades modernas que, no entanto, não prejudiquem o eco sistema. Grande responsável pelos danos negativos ao meio ambiente nos nossos dias atuais é o aumento desordenado da população e o crescimento urbano populacional (DALLABONA; DALLABONA, 2007).

Sendo assim, o crescimento populacional desordenado acaba por aumentar o uso dos recursos naturais e a exploração do meio ambiente. $\mathrm{O}$ aumento da população causa impactos ambientais pois diminui a abundância de recursos ambientais e faz com que as espécies nativas da região tenham que migrar para outras regiões e só retornem quando e se a região for recuperada. Caso contrário em algumas situações a espécie pode entrar em extinção. Nesse sentido a Ecologia Humana tem como objetivo analisar de maneia geral todas as espécies, para ter uma visão mais fiel e realista da sustentabilidade do nosso planeta (ALVIM; BADIRU; MARQUES, 2014).

Alguns grupos apresentam uma vida próxima do ideal da sustentabilidade, onde os consumos desses indivíduos acabam por ser apenas para as coisas básicas de uso doméstico com uso de recursos naturais, como é o exemplo de comunidades ribeirinhas ou agrícolas que tem um modo de vida isolado (RAMALHO, 2007; ALVIM, 2012).

Nesse sentido, o grau de sustentabilidade de grupos como o descrito acima depende em sua grande parte das necessidades dos indivíduos que compõem o grupo, adquirindo apenas o necessário para consumo e vestimenta, sem a idealização de acúmulo de bens (ALVIM; BADIRU; MARQUES, 2014).

O consumismo acaba por afetar o futuro do nosso planeta, pois o ser humano moderno muitas vezes cria padrões de comportamentos que exige do meio ambiente muito além do que ele poderia nos oferecer. Além do grande aumento populacional, existe também a questão do consumismo como já foi discutido acima. Nesse sentido, Albuquerque (2007) acrescenta que o crescimento populacional atual é incompatível com a nossa realidade de planeta com recursos finitos. O crescimento do consumo individual torna a situação mais urgente de intervenções, sendo de extrema necessidade adotarmos novos padrões de comportamentos para um novo modelo de desenvolvimento da humanidade.

Nossa sociedade ainda possui resistências acerca do que é o desenvolvimento sustentável e como podemos lidar com isso, como afirma Albuquerque (2007, p .83) "O grande problema é que o modelo atual de desenvolvimento, além de ignorar a existência 
de limites ecológicos, não cresce em função das necessidades humanas, e sim de sua própria dinâmica interna, uma vez que o crescimento é para ele um fim e não um meio".

Albuquerque (2007) sugere o modelo de desenvolvimento sustentável, baseado nas seguintes premissas: dependência do suprimento externo contínuo de energia que é o sol, uso racional da energia e da matéria com ênfase à conservação diminuindo o consumismo, reciclagem e reutilização dos materiais, controle da poluição gerando menos resíduos, controle do crescimento populacional em níveis sustentáveis, buscando a estabilização populacional.

É de grande relevância observarmos que é necessário restabelecer e reorganizar as bases da nossa sociedade, de forma que ela seja mais justa e igualitária, promovendo condições para a sobrevivência de todos. Para que isso seja praticável, e necessário que aqueles que tenham riquezas acumuladas abram mãos de parte de seus bens, para aqueles que pouco possuem ou nada tem para sua sobrevivência (ALBUQUERQUE, 2007).

\section{CONSIDERAÇÕES FINAIS}

Através do estudo da Ecologia Humana com foco nas relações entre homem e meio ambiente juntamente com a proposta de intervenção para uma exploração sustentável procura-se criar mecanismos eficientes que possam ajudar o nosso mundo atual e futuro a se desenvolver de forma sustentável, sem danos negativos ao nosso ecossistema que são causados pelo estilo de vida do homem contemporâneo.

As propostas enfatizadas no trabalho como o planejamento ambiental, a educação ambiental e o desenvolvimento sustentável são propostas que poderiam contribuir para que os danos que o ser humano está causando no meio ambiente possam diminuir e evitar catástrofes ambientais e até mesmo a extinção da raça humana e animal, pois com o aumento da população e a exploração exaustiva dos recursos naturais, o meio ambiente não irá suportar por muito tempo suprir o consumismo humano.

Nota-se a importância que o homem tem em seu habitat, e o quanto seus comportamentos podem afetar de maneira negativa ou positiva a vida de todos os seres que habitam o planeta. Através dos dados obtidos podemos verificar que com o aumento populacional mundial, será necessário criar meios para que haja a sustentação desses indivíduos de maneira que não interfira negativamente nos recursos naturais, pois como observado as nossas riquezas naturais estão inteiramente ligadas ao nosso bem-estar e

Educação, Psicologia e Interfaces, Volume 3, Número 2, p. 121-135, Maio/Agosto, 2019.

ISSN: 2594-5343. DOI: https://doi.org/10.37444/issn-2594-5343.v3i2.131 
sobrevivência na terra, e não apenas para nos alimentar ou saciar nossas necessidades ou consumismo.

É através da conscientização do dever do homem na terra que poderá fomentar uma sociedade mais justa e igualitária, de maneira que todos possam sobreviver e ter qualidade de vida. O planeta terra possui recursos naturais finitos, que se utilizados indiscriminadamente podem chegar a sua exaustão. Por esse motivo é necessário que o ser humano busque ações sustentáveis e tenha um papel ativo em sua comunidade para assim fomentar o conhecimento acerca dessa problemática atual.

É através de novos comportamentos sustentáveis que os danos provocados ao meio ambiente podem ser diminuídos, e assim manter a sobrevivência das espécies na terra.

\section{REFERÊNCIAS BIBLIOGRÁFICAS}

ALBUQUERQUE, B. P. As relações entre o homem e a natureza e a crise sócioambiental. Rio de Janeiro, RJ. Escola Politécnica de Saúde Joaquim Venâncio, Fundação Oswaldo Cruz (Fiocruz), 2007.

ALVIM, R. G. Ecologia Multidisciplinar - visão ética e social da problemática ambiental. Revista Kawaii, n. 2, p. 161-174, Jul-Dec. 2008.

ALVIM, R.G. Ecologia Humana: Da visão acadêmica aos temas atuais. MaceióAlagoas: Edufal, 2012.

ALVIM, R.G.; BADIRU, A.I.; MARQUES, J. Ecologia Humana. Feira de Santana-BA.: UEFS, 2014.

BEGOSSI, A. Ecologia Humana: Um Enfoque Das Relacões Homem-Ambiente. INTERCIENCIA 18(1): 121-132. 1993. Disponível em: http://www.interciencia.org.ve

BOFF, L. Revista Caros Amigos, São Paulo, set. 1998.

CAPRA, F. A teia da Vida. Cultrix. São Paulo. 1996

CAMPOS, P. C. ECOLOGIA HUMANA: O pressuposto da Ética na preservação do Meio Ambiente, Breve história sobre origens e conceitos do Movimento Ambientalista. Eca-USP.2006.

CASSINI, S.T. Ecologia: Conceitos Fundamentais. Vitória: UFES, 2005.

DALLABONA, C.A. Da gestão da informação à complexidade e à sustentabilidade. VII SINCONEE/III GEDOC. Anais. Florianópolis. 2006. 
DALLABONA, T.M. \& DALLABONA, A.D. Ecologia Humana - Uma abordagem necessária nos cursos de engenharia e arquitetura. XXXV Congresso Brasileiro de Educação em Engenharia - COBENGE, Curitiba. 2007.

GLOBAL FOOTPRINT NETWORK. Disponível em: http://www.footprintnetwork.org/en/index.php/GFN/page/world_footprint/. Acesso em: 21 Dez. 2018.

KUPSTAS, Marcia (org). Ecologia em debate. Editora Moderna. São Paulo, 1997.

LEFF, E. Saber ambiental. 3. ed. Petrópolis: Vozes, 2001.

MENDONÇA, Rita. Conservar e criar: natureza, cultura e complexidade. Editora Senac São Paulo. São Paulo, 2005.

MINISTÉRIO DO MEIO AMBIENTE. Documento Online. Sustainable Production \& Consumption: Making the Conection. Sessão II. Contexto global de consumo e produção sustentáveis. Padrões de consumo atuais. 2016. Disponível em: http://www.mma.gov.br/estruturas/a3p/_arquivos/consumo_producao_sustentavel.pdf. Acesso em: 08 Dez. 2018.

MOLINA, S. M. G; LUI, G. H.; SILVA, M. P. A ecologia humana como referencial teórico e metodológico para a gestão ambiental. OLAM Ciência \& Tecnologia, v. 7, n. 2. Rio Claro. 2007.

NEDER, R. T. Crise socioambiental. Estado \& sociedade civil no Brasil (1982-1998). São Paulo: Annablume, 2002.

ONUBR NAÇÕES UNIDAS DO BRASIL. Documento online. Apesar de baixa fertilidade, mundo terá 9,8 bilhões de pessoas em 2050. 2018

. Disponível em: < https://nacoesunidas.org/apesar-de-baixa-fertilidade-mundo-tera-98bilhoes-de-pessoas-em-2050/> . Acesso em: 08 Dez. 2018.

RAMALHO, C. W. N. Embarcadiços do encantamento: trabalho como arte, estética e liberdade na pesca artesanal de Suape, PE. 2007. 300f. Tese (Doutorado em Ciências Sociais). Universidade Estadual de Campinas, 2007.

REIGOTA, Marcos. O que é educação ambiental. Editora Brasiliense: Coleção Primeiros Passos. São Paulo, 2004.

ROOS, A.; BECKER, E. L. S. Educação Ambiental e Sustentabilidade. Revista Eletrônica em Gestão, Educação e Tecnologia Ambiental, v.5 , n. 5, p. 857 - 866, 2012.

SOUZA, T. C.; SILVA, E. V. Planejamento e gestão ambiental: análise integrada da Praia de Canoa Quebrada em Aracati- Ce. VI Seminário Latino Americano de Geografia Física II Seminário Ibero Americano de Geografia Física Universidade de Coimbra, Maio de 2010.

TRIGUEIRO, André. Mundo Sustentável: abrindo espaço na mídia para um planeta em transformação. São Paulo: Globo, 2005.

Educação, Psicologia e Interfaces, Volume 3, Número 2, p. 121-135, Maio/Agosto, 2019.

ISSN: 2594-5343. DOI: https://doi.org/10.37444/issn-2594-5343.v3i2.131 
UN DESA. Documento online. Perspectivas da População Mundial: a Revisão 2017. Disponível em: < https://www.un.org/development/desa/publications/world-populationprospects-the-2017-revision.html> . Acesso em: 08 Dez. 2018.

\section{Credenciais da/os autora/es}

BARROS, Dominique Rodrigues. Centro Universitário de Mineiros - UNIFIMES Brasil. E-mail: dominiquepsicologiarh@gmail.com

SILVA, Monique Nogueira da. Centro Universitário de Mineiros - UNIFIMES - Brasil. E-mail: monique1205nog@gmail.com

Endereço para correspondência: Dominique Rodrigues Barros. E-mail: dominiquepsicologiarh@gmail.com

Como citar este artigo (Formato ABNT): BARROS, Dominique Rodrigues; SILVA, Monique Nogueira da. A conscientização do homem para uma exploração sustentável do meio ambiente. Educação, Psicologia e Interfaces, v. 3, n.2, p.121-135, 2019. DOI: https://doi.org/10.37444/issn-2594-5343.v3i2.131

Recebido: 04/03/2019.

Aceito: 20/6/2019. 